\title{
World Journal of Surgical minimal invasive left atrial decompression during venoarterial extracorporeal membrane oxygenation for pediatric acute fulminant myocarditis
}

Li Fen Ye, ${ }^{1}$ Qiang Shu (D , ${ }^{1}$ Chenmei Zhang, ${ }^{2}$ Yong Fan, ${ }^{1}$ Liyang Ying, ${ }^{1}$ Lijun Yang, ${ }^{3}$ Ru Lin (1) ${ }^{1}$

To cite: Ye LF, Shu Q, Zhang C, et al. Surgical minimal invasive left atrial decompression during venoarterial extracorporeal membrane oxygenation for pediatric acute fulminant myocarditis. World Jnl Ped Surgery 2021;4:e000291. doi:10.1136/wjps-2021-000291

Accepted 12 August 2021

\section{Check for updates}

(c) Author(s) (or their employer(s)) 2021. Re-use permitted under CC BY-NC. No commercial re-use. See rights and permissions. Published by BMJ.

${ }^{1}$ Heart Institute, Zhejiang University School of Medicine Children's Hospital, Hangzhou, Zhejiang, China

${ }^{2}$ Pediatric Intensive Care Unit, Zhejiang University School of Medicine Children's Hospital, Hangzhou, Zhejiang, China ${ }^{3}$ Extracorporeal Circulation and Extracorporeal Life Support, Zhejiang University School of Medicine Children's Hospital, Hangzhou, Zhejiang, China

Correspondence to Ru Lin; linru.008@zju.edu.cn
Venoarterial extracorporeal membrane oxygenation (VA ECMO) has been considered as the first-line treatment for acute fulminant myocarditis (AFM) when traditional treatment is ineffective. Peripheral vascular VA ECMO can partially reduce right ventricular preload, but it can increase left ventricular (LV) afterload. ${ }^{1}$ The increased afterload may cause difficulty in LV blood ejection in patients with severely impaired LV function. In addition, it may result in secondary LV dilatation, pulmonary edema, intraventricular thrombosis, and even increased LV diastolic pressure, leading to myocardial ischemia and irreversible cardiac function, affecting the prognosis of the disease. ${ }^{2}$ Timely LV decompression can help to improve the prognosis. ${ }^{3}$ Here, we report a successful case of applying a surgical minimal invasive left atrial decompression method, and we discuss the appropriate timing and method of LV decompression during ECMO supporting in pediatric AFM.

A 2-year-old girl with AFM was implanted with VA ECMO because of cardiac shock refractory to conventional therapy. The pulse pressure difference was less than $10 \mathrm{~mm} \mathrm{Hg}$, the LV ejection fraction (LVEF) was $20 \%$ and the LV dilated diameter (LVDD) was $36 \mathrm{~mm}$ while ECMO initiated. In addition, fluid intake was limited to $60 \%$ of normal physiological requirements. Epinephrine was maintained at $0.3 \mu \mathrm{g} /$ $\mathrm{kg} / \mathrm{min}$. ECMO blood flow was titrated to mean arterial blood pressure (MABP) $>50 \mathrm{~mm} \mathrm{Hg}$ and venous oxygen saturation $>65 \%$ to reduce $\mathrm{LV}$ afterload as low as possible. Urine output and serum lactate were monitored. On the 24th hour of ECMO running, the MABP increased to $80 \mathrm{~mm} \mathrm{Hg}$ and pulse pressure difference declined to less than $5 \mathrm{~mm} \mathrm{Hg}$. Echocardiography showed that the LVEF decreased to $10 \%$, LVDD increased to $41 \mathrm{~mm}$, and only a small amount of blood ejected to the aorta (figure 1). Therefore, a surgical minimal invasive inserted left atrial venting cannula method was adopted to unload LV. The procedure was performed by two experienced cardiology surgeons at the bedside. The left atrial was exposed via anterolateral thoracotomy through the fourth intercostal space. A 14 Fr straight cardiopulmonary bypass venous cannula (Flyer, Ningbo, China) was inserted into left atrial appendage (figure 2) and was connected to the venous limb of ECMO circuit with a ' $\mathrm{Y}$ ' connector. On the 36th of LV decompression, pulse pressure increased to $15 \mathrm{~mm} \mathrm{Hg}$, LVEF increased to $25 \%$ and LVDD decreased to $33 \mathrm{~mm}$. Aortic valve motion was improved. Then the LV decompression cannula was clamped intermittently to assess LV function for about 4 hours until withdrawal. Major chest hemorrhage occurred on the night of the removal of the LV decompression cannula. Surgical debridement was performed at the bedside to hemostasis. Six hundred millilitres of hematoma was removed, and the surgical wound was sutured strictly. On day 7 after ECMO initiation, LVEF increased to $47 \%$ on epinephrine $0.2 \mu \mathrm{g} / \mathrm{kg} /$ $\mathrm{min}$, and norepinephrine $0.1 \mu \mathrm{g} / \mathrm{kg} / \mathrm{min}$ was applied. Then, ECMO was weaned off successfully. Ventilator was weaned off although the patient had atelectasis of the left lung 7 days after ECMO explanted. Physical examination showed paralysis of left upper extremity (muscle strength grade 1) when she was awake. Cranial computer tomography (CT) scan of the brain indicated infraction in the right basal ganglia and lateral paraventricular area infarction. She was transferred to a rehabilitation hospital for hyperbaric oxygen therapy after recovery of heart function. The patient's left upper limb muscle strength recovered to grade 3 after 1 month of treatment. 


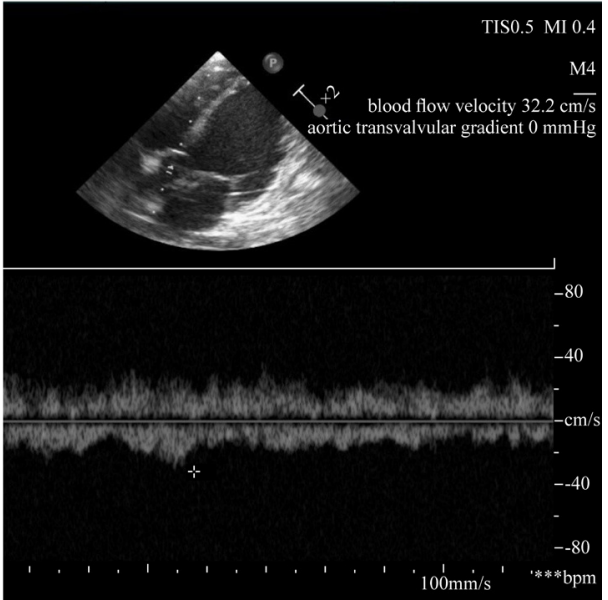

Figure 1 Echocardiography showed the aortic valve blood flow velocity was $32.3 \mathrm{~cm} / \mathrm{s}$ and the aortic transvalvular gradient was $0 \mathrm{~mm} \mathrm{Hg}$, indicating decreasing blood from native left ventricle to aorta.

The timing of LV decompression in children is still controversial. ${ }^{4}$ The precise evidence of LV distension is elevated LV end diastolic pressure obtained by Swan-Ganz catheter. But it was gradually replaced by less or non-invasive technology. ${ }^{5}$ Kim et al considered LV decompression when patients showed progressive pulmonary congestion on chest radiography or pink frothy expectoration, and low pulse pressure. ${ }^{6}$ We adopted non-invasive methods including restricting fluids, adjusting drugs and ECMO flow to reduce the LV afterload since the initiation of ECMO. LV function had been assessed closely using echocardiography. The decision to perform LV decompression was based on the situation of LV dilatation, aortic valve opening difficulty or even closing and echo LV 'smoke' sign. In addition, the progressive decreasing arterial pulse pressure indicated no cardiac output. Continuing flat arterial waveform can be a warning sign that LV decompression is required. Another consideration is the duration between LV decompression

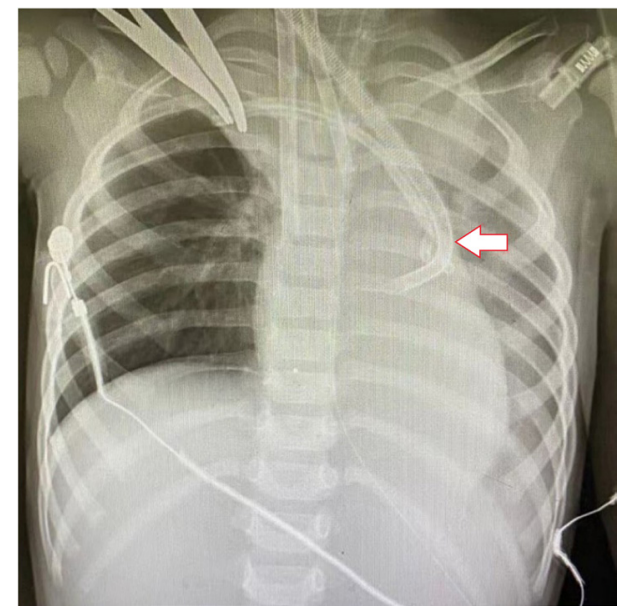

Figure 2 Chest X-ray indicated venous cannula was inserted into left atrium through the fourth intercostal space (red arrow) and the tip of the cannula was located at left atrial appendage. and initiation of ECMO. The current literature indicated that earlier LV decompression might be beneficial to minimize risks related to prolonged ECMO. According to experience with better clinical results, LV decompression was performed 18 hours, ${ }^{7} 11$ hours, ${ }^{8}$ or even 2.61 hours ${ }^{3}$ after ECMO initiation. Generally speaking, the cardiac function is worst at the early stage of ECMO implantation. It is necessary to monitor hemodynamic data closely and to establish LV decompression in time.

There is no consensus on the appropriate method for LV decompression. ${ }^{6}$ In pediatric patients, decompression of the left heart has been attempted through balloon atrial septostomy, blade atrial septostomy, blade-and-balloon atrial septostomy and direct surgical LV venting. ${ }^{2}$ Balloon atrial septostomy to reduce left atrial and ventricular pressures by a left-to-right shunt has been used in neonates, children and adults. Yet, it can be technically difficult to create an appropriately sized defect. ${ }^{2}$ The blade atrial septostomy approach, which needs surgical correction in case of myocardial recovery, was mainly recommended for patients with bridging transplantation or LV assistant device. ${ }^{2}$ Transvenous intubation through atrial transseptal into the left atrium or ventricle has been successfully applied in children. ${ }^{9}$ Direct surgical venting method was mostly used in patients requiring ECMO for failure to wean from cardiopulmonary bypass. ${ }^{7}$ This approach allows larger sized cannula compared with percutaneous approaches, which improves venous drainage and substantial LV unloading, yet still carry substantial risks of bleeding. ${ }^{2}$ We employed this method to effectively improve the patient's LV function. Despite the use of minimally invasive small incision technology, the patient still complicates with hemorrhage. It can be seen that strict surgical hemostasis is an important issue.

We advocated that heart unloading should be considered when peripheral VA ECMO was initiated to rescue cardiac function failure. LV decompression should be established timely when the left heart was still difficult to output blood after conventional treatment. Surgical methods are effective methods for children's left heart decompression. Therefore, strict surgical hemostasis is important to prevent bleeding complications.

Acknowledgements We thank patients and their parents for allowing us to publish this case report.

Contributors LFY contributed to conceptualisation and original drafting. QS contributed to conceptualisation. CZ contributed to conceptualisation. RL contributed to conceptualisation. YF contributed to formal analysis. LYY contributed to formal analysis. LJY contributed to original drafting.

Funding The authors have not declared a specific grant for this research from any funding agency in the public, commercial or not-for-profit sectors.

Competing interests QS is the Editor in Chief for World Journal of Pediatric Surgery. The paper was handled by the other Editor and has undergone rigrous peer review process. QS was not involved in the journal's review of, or decisions related to, this manuscript.

Patient consent for publication Parental consent has been obtained.

Ethics approval Study ethics approval was obtained on 31 December 2020 (approval number: 2020-IRB-196).

Provenance and peer review Not commissioned; externally peer reviewed. 
Data availability statement All data relevant to the study are included in the article or uploaded as supplemental information. All free text entered below will be published.

Open access This is an open access article distributed in accordance with the Creative Commons Attribution Non Commercial (CC BY-NC 4.0) license, which permits others to distribute, remix, adapt, build upon this work non-commercially, and license their derivative works on different terms, provided the original work is properly cited, appropriate credit is given, any changes made indicated, and the use is non-commercial. See: http://creativecommons.org/licenses/by-nc/4.0/.

ORCID iDs

Qiang Shu http://orcid.org/0000-0002-4106-6255

Ru Lin http://orcid.org/0000-0001-8319-4995

\section{REFERENCES}

1 Broomé M, Donker DW. Individualized real-time clinical decision support to monitor cardiac loading during venoarterial ECMO. J Trans/ Med 2016;14:4

2 Donker DW, Brodie D, Henriques JPS, et al. Left ventricular unloading during veno-arterial ECMO: a review of percutaneous and surgical unloading interventions. Perfusion 2019;34:98-105.
3 Kotani Y, Chetan D, Rodrigues W, et al. Left atrial decompression during venoarterial extracorporeal membrane oxygenation for left ventricular failure in children: current strategy and clinical outcomes. Artif Organs 2013;37:29-36.

4 Rupprecht L, Flörchinger B, Schopka S, et al. Cardiac decompression on extracorporeal life support: a review and discussion of the literature. Asaio J 2013;59:547-53.

5 Chen Y-YK, Desai SP, Fox JA. Literature and new innovations leading to the rise and fall of the Swan-Ganz catheter. J Anesth Hist 2020;6:21-5.

$6 \mathrm{Kim} \mathrm{S}$, Kim JS, Shin JS, et al. How small is enough for the left heart decompression cannula during extracorporeal membrane oxygenation? Acute Crit Care 2019;34:263-8

7 Zampi JD, Alghanem F, Yu S, et al. Relationship between time to left atrial decompression and outcomes in patients receiving venoarterial extracorporeal membrane oxygenation support: a multicenter pediatric interventional cardiology early-career Society study. Pediatr Crit Care Med 2019;20:728-36.

8 Aiyagari RM, Rocchini AP, Remenapp RT, et al. Decompression of the left atrium during extracorporeal membrane oxygenation using a transseptal cannula incorporated into the circuit. Crit Care Med 2006;34:2603-6.

9 Swartz MF, Smith F, Byrum CJ, et al. Transseptal catheter decompression of the left ventricle during extracorporeal membrane oxygenation. Pediatr Cardiol 2012;33:185-7. 